MISS DANIQUE RM VLASKAMP (Orcid ID : 0000-0002-6820-8268)

Article type : Full length original research paper

\title{
Schizophrenia is a later-onset feature of PCDH19 Girls Clustering Epilepsy
}

Danique R.M. Vlaskamp, MD ${ }^{1,2}$, Anne S. Bassett, MD, FRCPC ${ }^{3,4,5}$, Joseph E. Sullivan, MD ${ }^{6}$, Jennifer Robblee, MD, FRCPC ${ }^{7}$, Lynette G. Sadleir, MBChB, MD ${ }^{8}$, Ingrid E. Scheffer, MBBS, PhD, FRACP ${ }^{1,9,10^{*}}$, Danielle M. Andrade, MD, MSc, FRCPC ${ }^{7,11^{*}}$

1 Epilepsy Research Centre, Department of Medicine, the University of Melbourne, Austin Health, Melbourne, Australia

2 University of Groningen, University Medical Center Groningen, Department of Neurology and Department of Genetics, Groningen, the Netherlands

3 Clinical Genetics Research Program, Centre for Addiction and Mental Health, and Campbell Family Mental Health Research Institute, Toronto, ON, Canada

4 Department of Psychiatry, University of Toronto, Toronto, ON, Canada

5 Dalglish Family 22q Clinic for Adults with 22q11.2 Deletion Syndrome and Toronto General Research Institute, University Health Network, Toronto, ON, Canada

6 University of California San Francisco, Pediatric Epilepsy Center, Benioff Children's Hospital, San Francisco, CA, Unites States

7 Division of Neurology, Toronto Western Hospital, University of Toronto, Toronto, ON, Canada

8 Department of Paediatrics and Child Health, University of Otago, Wellington, New Zealand

9 Department of Paediatrics, The University of Melbourne, Royal Children's Hospital, Victoria, Australia

This is the author manuscript accepted for publication and has undergone full peer review but has not been through the copyediting, typesetting, pagination and proofreading process, which may lead to differences between this version and the Version of Record. Please cite this article as doi: $10.1111 /$ EPI.14678

This article is protected by copyright. All rights reserved 
The Florey Institute of Neurosciences and Mental Health, Melbourne, Victoria, Australia

Toronto, Toronto, ON, Canada

*These authors contributed equally

\section{Corresponding authors:}

Prof Ingrid E. Scheffer

Melbourne Brain Centre, 245 Burgundy Street, Heidelberg, Victoria 3084, Australia

Tel: +61 390357112 Fax: +61394962291

Email: i.scheffer@unimelb.edu.au

A/Prof Danielle M. Andrade

Toronto Western Hospital, 5W-445, 399 Bathurst Street, Toronto, ON, Canada, M5T 2S8

Tel: 1-416-603-5927 Fax: 1-416-603-5768

Email: Danielle.Andrade@uhn.ca

Key Words: Psychotic disorders, psychosis, psychiatry, epilepsy, seizures

$\begin{array}{ll}\text { Number of text pages: } & 26 \\ \text { Number of words: } & 3036 / 4000 \\ \text { Number of references: } & 45 / 50 \\ \text { Number of figures: } & 1 \\ \text { Number of tables: } & 2\end{array}$

\section{Abstract}

Objective. To investigate the occurrence of psychosis and serious behavioural problems in females with $\mathrm{PCDH} 19$ pathogenic variants.

Methods. We evaluated whether psychosis and serious behavioural problems had occurred in 60 females (aged 2-75 years) with $P C D H 19$ pathogenic variants, belonging to 35 families.

Patients were identified from epilepsy genetics databases in Australia, New Zealand, US and Canada. Neurological and psychiatric disorders were diagnosed using standard methods.

Results. 8/60 (13\%) females from 7 families developed a psychotic disorder: schizophrenia (6), schizoaffective disorder (1) or an unspecified psychotic disorder (1). Median age at onset of psychotic symptoms was 21 years (range 11-28 years). In our cohort of 39 females aged 11 
years or above, $8(21 \%)$ developed a psychotic disorder. Seven had ongoing seizures at onset of psychosis, with two continuing to have seizures when psychosis recurred. Psychotic disorders occurred in the setting of mild (4), moderate (2) or severe (1) intellectual disability or normal intellect (1). Pre-existing behavioural problems occurred in four females, and autism spectrum disorder in three. Two (3\%) additional females had psychotic features with other conditions: an adolescent had recurrent episodes of post-ictal psychosis and a 75 year old woman had major depression with psychotic features. A further three (5\%) adolescents with moderate to severe intellectual disability had onset of severe behavioural disturbance, or significant worsening, in adolescence.

Significance. We identify that psychotic disorders, including schizophrenia, are a later onset manifestation of PCDH19 Girls Clustering Epilepsy. Affected girls and women should be carefully monitored for later-onset psychiatric disorders.

Key Words: Psychotic disorders, psychosis, psychiatry, epilepsy, seizures

\section{Introduction}

PCDH19 pathogenic variants (OMIM 300460) were initially identified in a family with Epilepsy and Mental Retardation limited to Females (EFMR, OMIM 300088). ${ }^{1,2}$ However, as about one-quarter of women do not have mental retardation, ${ }^{1,3}$ the new name of Girls Clustering Epilepsy (GCE) was suggested to aid recognition of this distinctive disorder with an unusual inheritance pattern. ${ }^{4}$ PCDH19-GCE occurs in heterozygous females, while males are usually unaffected transmitting carriers. Rare males with mosaic pathogenic variants are affected, reflecting the female pattern of two X chromosomes and the consequent coexistence of cells with and without mutant $P C D H 19 .{ }^{2,5,6}$ Girls with $P C D H 19$ pathogenic variants present with recurrent clusters of seizures triggered by fever in infancy or early childhood. Intellect can range from normal to severe intellectual disability (ID). ${ }^{1,2,7}$

While psychiatric features were noted in a few females reported in the original studies of PCDH19-GCE (called EFMR in these studies), ${ }^{1,8,9}$ behavioural and psychiatric comorbidities are common, and may pose the most disabling problem in adulthood. ${ }^{3}$ An array of psychiatric co-morbidities has been described including severe behavioural problems, obsessive features and autism spectrum disorder. In adult life, we previously reported two women with a schizophreniform psychosis ${ }^{1}$ and an additional woman with psychosis has been subsequently reported. $^{10}$ 
We hypothesized that psychosis was a later-onset feature of PCDH19-GCE. We therefore analysed the presence of psychosis and serious behavioural problems in a cohort of females with $P C D H 19$ pathogenic variants.

\section{Methods}

\section{Study cohort}

Patients were ascertained from the epilepsy genetics databases of the authors located in Australia and New Zealand, the United States, and Canada. These databases include all patients presenting with genetic epilepsy and their relatives who consent to research participation. The database includes information on pathogenic variants. Families A, B, E and G were previously published ${ }^{1,2,11,12}$, however, their psychiatric phenotype has been evaluated in detail for this study. We analyzed the frequency of psychosis in adolescent and adult women with a $P C D H 19$ pathogenic variant, using the youngest age of onset of psychosis observed in our cohort to delineate the group of interest.

\section{Phenotyping}

We use the term 'PCDH19-Girls Clustering Epilepsy' (PCDH19-GCE) for the wellrecognised epilepsy syndrome associated with $P C D H 19$ pathogenic variants, as previously suggested. ${ }^{4,13,14}$ We examined whether each female had experienced psychosis and serious behavioural problems and the evolution of these symptoms over time. We also evaluated the epilepsy phenotype, developmental course and intellect, magnetic resonance imaging (MRI), and genetic results, and the family history. Information was obtained using a validated seizure questionnaire, ${ }^{15}$ clinical interviews and review of medical records. Psychotic disorders were diagnosed using the fifth edition of the Diagnostic and Statistical Manual of Mental disorders (DSM-V) by an academic psychiatrist (ASB), after local assessment by a psychiatrist at time of the patient's presentation. ${ }^{16}$ The level of intellectual disability was based on IQ scores obtained through formal psychometric assessment. Seizure types and epilepsy syndromes were classified according to the 2017 International League Against Epilepsy Classification of the Epilepsies. ${ }^{17,18}$

\section{Genotyping}

PCDH19 is a highly conserved gene as illustrated by its intolerance to variation (Residual Variation Intolerance Score (RVIS) = -0.89) and to loss of function variation (probability of intolerance to loss of function $(\mathrm{pLI})$ score $=1.00) .{ }^{19}$ In the research genetic epilepsy database, 
only pathogenic variants were included, based on the criteria of the American College of Medical Genetics. ${ }^{19}$ We present the data on pathogenic variants identified in females with a psychotic disorder in Supplemental Table 1. PCDH19 pathogenic variants or deletions were reported in accordance with its longest isoform 1 (NM_001184880.1).

\section{Ethical statement}

Patients, or their parents or legal guardians in the setting of minors or those with intellectual disability, gave written informed consent for inclusion in our study. This study was approved by the local institutional Human Research Ethics Committee (Austin Health reference H2007/02961), the Health and Disability Ethics Committee (New Zealand) and the Research Ethics Board (Toronto Western Hospital 15-9512).

\section{Results}

We studied 60 females with $P C D H 19$ pathogenic variants, from 35 families. Females were aged between 2 and 75 years (median age 18 years).

\section{PCDH19 Girls Clustering Epilepsy with chronic psychotic disorders (n= 8)}

Eight of our cohort of 60 females developed a psychotic disorder. Median age at study of these eight females was 31 years (range 21-64 years). Psychosis began in adolescence and adult life at a median age at onset of 21 years (range 11-28 years). When we analysed our cohort aged 11 years (youngest age at onset of psychosis in our cohort) or older, we found that $8 / 39(21 \%)$ females were affected with a psychotic illness. The case histories of two women with PCDH19-GCE and a psychotic disorder are described in the Supplementary data.

The eight females came from seven families (Figure 1). Six (15\%) had schizophrenia, of whom two were sisters (family D), one (3\%) had a schizoaffective disorder and one (3\%) an 'unspecified schizophrenia spectrum and other psychotic disorder' (Table 1). One female had childhood onset schizophrenia from age 11 years. Two had a co-existing psychiatric diagnosis; one had post-traumatic stress disorder (after a sexual assault) and another had a major depressive disorder.

In 7 women, the initial episode of psychosis markedly varied in duration between 1-2 weeks and 5 years. The remaining woman (E:II:4) had frequent ongoing hallucinations from 11 to 
27 years. Six women had recurrent psychotic episodes. Psychotic symptoms included disorganised motor behaviour (8) including catatonia in 1, hallucinations (7), delusions (6), negative symptoms (5) and disorganised thinking (3). Antipsychotic medication was commenced in all eight females and was effective in all but one (E:II:4). Two females also had a positive response to a selective serotonin-reuptake inhibitor (SSRI, sertraline) or to a selective serotonin-norepinephrine reuptake inhibitor (SNRI, duloxetine).

Three women had autism spectrum disorder (ASD) diagnosed at age 3.5 - 12 years, 7 to 12 years prior to their presentation with psychosis; five women did not have a diagnosis of ASD. Behavioural problems in childhood or adolescence were already present before the onset of psychotic symptoms in four females, and included aggression and anxiety (3), and behavioural problems with suicidal gestures (1). Only one female (C:II:1) was on psychotropic medication, an anti-depressant, and this was discontinued when she discovered she was pregnant, prior to onset of psychosis later in pregnancy.

The psychotic disorders occurred with co-morbid ID in 7/8 females which was mild in four, moderate in two and severe in one. The remaining patient had borderline intellect. A decline in scholastic abilities preceded psychotic symptoms in one adolescent (D:IV:2) aged 18 years with mild ID. A 19 year old adolescent (G:IV:4) with moderate ID had cognitive regression associated with romantic obsessions; following an episode of status epilepticus, she developed erotomanic delusions. In four patients, social withdrawal was observed with the initial or recurrent episode of psychosis.

All eight females had a history of seizures. In one woman, seizures had resolved 15 years prior to psychosis onset. The remaining seven had ongoing seizures and were on antiepileptic medication at the onset of psychosis. Seizures had resolved in three women one to four years before their psychosis recurred. For the 27 year old woman (E:II:4) with childhood onset schizophrenia beginning at 11 years, seizures settled at age 15 years, although hallucinations persisted throughout adult life. The remaining three females had ongoing seizures including bilateral tonic-clonic seizures (3), focal impaired awareness seizures (2), tonic seizures (2), absences (1) and febrile seizures (1) with seizure frequencies varying from every few weeks to breakthrough seizures only associated with medication change.

Neuroimaging performed in 7/8 patients (CT-2, MRI-5) was normal. 


\section{Females with secondary psychotic symptoms $(n=2)$}

Two women in our cohort had psychotic symptoms that did not fulfil a diagnosis of a 'schizophrenia spectrum or other psychotic disorder'. A 17 year old adolescent with a de novo p.Glu201Pro PCDH19 pathogenic variant (patient H) and moderate ID developed recurrent post-ictal psychosis, comprising auditory and visual hallucinations, following clusters of seizures from the age of 14 years. She has not yet received anti-psychotic medication, because her psychotic episodes have been post-ictal and self-limiting.

The matriarch of family A (Figure), patient A:I:3, underwent abdominal surgery for a bowel obstruction at 75 years and developed a major depression. Associated with this depression, she had ongoing psychotic features including visual hallucinations of people from her past hitting her. Treatment with citalopram, topiramate and levetiracetam (the latter two for seizures) did not improve her depression or psychotic symptoms.

\section{Adolescents with serious behavioural problems $(\mathrm{n}=\mathbf{3})$}

In the remaining 50/60 females without a psychotic disorder or psychotic symptoms, severe behavioural problems were present in 15/50 (30\%). For three girls with moderate to severe ID, behavioural problems were extremely severe and disruptive to the families' life in adolescence and adult life, rendering them housebound; and resulting in police visits to ensure safety due to the severity of the patient's aggression (Table 2). Behavioural problems began in childhood, but became much more severe at age 10-12 years. Anti-psychotic treatment was effective in one, ineffective in another, and whether anti-psychotic treatment was prescribed for the third was not known. It was not possible to classify these behavioural problems as a schizophrenia spectrum or other psychotic disorder due to the lack of obvious signs of hallucinations or delusions in these adolescents with severe intellectual disability. Another girl (A:III:13) with severe ID developed extremely severe violent behaviour twice following a midazolam intravenous treatment for anaesthesia ( $<14$ years) and for seizures (14 years).

\section{Genotype-phenotype correlation}

No genotype-phenotype correlation for the occurrence of PCDH19-related psychotic and serious behavioural problems could be identified. The pathogenic variants of the eight females with the psychotic disorders occurred throughout the gene, and did not differ in location from those without psychotic disorders. The pedigrees show striking inter- and 
intrafamilial phenotypic heterogeneity of features including a spectrum of severity for epilepsy, intellectual disability, behavioural and psychiatric problems including psychotic disorders (Figure 1).

\section{Discussion}

PCDH19-related epilepsies typically present in infant girls who have clusters of seizures, often triggered by fever. The term PCDH19-Girl Clustering Epilepsy has been recently suggested to aid in earlier recognition of this serious disorder. ${ }^{4,13,14}$ The psychiatric features in childhood and adolescence of severe behavioural problems, obsessional features and ASD often prove more disabling for patients and families, even though seizures may have abated. ${ }^{1}$ Here we describe eight females with PCDH19-GCE who present with adolescent or adult onset psychotic disorder with prominent decline in functioning, of whom six satisfied a diagnosis of schizophrenia.

\section{Psychotic disorders in PCDH19-GCE}

We studied the presence of psychotic disorders in 60 females with PCDH19-GCE. As psychosis presented from the age of 11 years, we calculated the frequency in our 39 older females aged 11 years or older. We found that $21 \%$ of our older cohort developed psychotic disorders, most often classified as schizophrenia (15\% of total). This $21 \%$ figure is a minimum estimate of the frequency of psychotic disorders. Fourteen $(36 \%)$ of the 39 females are still younger than 29 years of age, which was the oldest age of onset of psychosis in our cohort.

Diagnosis of psychotic disorders in patients with comorbidities can be challenging. First, psychotic episodes in patients with ongoing seizures are often considered post-ictal phenomena. However, 4/8 females developed their initial or recurrent psychotic symptoms when they had been seizure-free for at least a year, such that their psychosis could not be considered post-ictal. Guidelines for the diagnosis of post-ictal psychosis indicate that the duration of psychosis should be less than two months yet, for three of our remaining four females with psychotic illness, the psychosis lasted from 18 months to 16 years. ${ }^{20,21}$ Second, three other women had concurrent behavioural or social deterioration with psychosis, supporting a diagnosis of a 'schizophrenia spectrum or other psychotic disorder'. 
Third, psychotic symptoms such as changes in thinking and speech are more difficult to recognize in patients with ID. While the women with mild ID or borderline intellect presented with a typical thought disorder, the woman with severe ID (E:II:4) had more subtle observable changes such as looking and smiling at the corners of a room. This was coupled with a major change in behaviour at age 11 years, presenting with severe aggression and running away from school. Not included in the eight patients with psychotic disorders was a 19 year old non-verbal adolescent with severe ID who developed odd post-ictal behavioural changes such as laughing at the toilet bowl. This behavior was only observed on two occasions and was insufficient to meet diagnostic criteria for a psychotic disorder.

Only one other female with $P C D H 19-G C E$ and psychosis has been reported ${ }^{10}$, in addition to our original report of two cases; the latter two are included in the eight patients reported here (Table 1$)^{1,2}$ The lack of additional published cases with psychotic disorders may be explained by the young age of the majority of girls with PCDH19-GCE. Recognition of this disease is rapidly increasing with greater access to genetic testing for children with infantile-onset seizures. In addition, many adolescent and adult women with ID and seizures are not offered genetic testing, despite recommendations for clinical testing. ${ }^{22,23}$ Moreover, the association of psychosis in a woman with a past history of seizures in childhood may not be considered as related to an underlying $P C D H 19$ pathogenic variant, even where the variant is known. Currently, there are nine PCDH19 mosaic males reported in the literature, of whom seven had behavioural problems, but they are too young (only three were aged 13 and 14 years) to determine whether they are at risk of psychosis. ${ }^{5,6,24,25}$ Longer term follow-up of women and mosaic men with PCDH19-GCE will clarify the risk of later-onset psychotic disorders.

It is possible that the severe behavioural problems seen in PCDH19-GCE could be a precursor to later-onset psychotic disorders in some patients (Table 2). In three additional adolescents with moderate to severe ID, we observed horrific and grossly disorganized behavioural problems. It is uncertain whether their behavioural regression in puberty could reflect thought disorder that is difficult to decipher given the severity of their cognitive impairment.

\section{Frequency of psychotic disorders in PCDH19-GCE}

The frequency of psychotic disorders (21\%), including schizophrenia (15\%), in our cohort of females with $\mathrm{PCDH} 19$ pathogenic variants was far higher than general population estimates 
of psychotic disorders (3.5\%) and schizophrenia (1.4\%) in the Finnish National Population Register. $^{26}$ The frequency is also higher than that found in cohorts with ID, ASD or epilepsy, where risk is elevated. In individuals with ID, the prevalence of psychotic disorders was $4.4 \%$ in a cohort of 1023 patients $^{27}$ and the prevalence of schizophrenia was 3.6\% of 13,295 patients. ${ }^{28}$ For patients with ASD and normal intellect, schizophrenia spectrum disorders occurred in $6 \%$ of 713 patients. ${ }^{29}$ Turning to epilepsy, psychosis (not further classified) was diagnosed in $5.6 \%$ of patients in a meta-analysis of 56 studies including more than 40,000 participants, and was most frequent in those with temporal lobe epilepsy (7\%). ${ }^{30}$

Risk for psychotic disorders in females with PCDH19-GCE appears to be more comparable to that of individuals with rare recurrent microdeletions and microduplications that are associated with schizophrenia. ${ }^{31}$ These include chromosome $22 \mathrm{q} 11.2$ deletions where schizophrenia and schizophrenia spectrum disorders develop in up to $25 \%$ of patients, ${ }^{32}$ and $15 \mathrm{q} 13.3$ deletions where $10.2 \%$ are reported to have schizophrenia. ${ }^{33}$ Other lower risk copy number variants have been reported in large scale population studies. ${ }^{34,35}$

Why only a fifth of women with $P C D H 19-G C E$ develop psychotic disorders remains to be elucidated. Our patients had pathogenic variants throughout PCDH19: in exon 1 (4), 2 (1) and 5 (1) and deletions in exon 6 (2). Larger numbers of affected women may enable genotype-phenotype correlations to emerge.

\section{Possible shared mechanisms between psychosis and PCDH19-GCE}

There may be shared disease mechanisms explaining the increased risk of psychosis in PCDH19-GCE, based on observations relating to hormonal manipulation and brain connectivity. First, psychotic disorders often begin in adolescence, when hormonal levels in the hypothalamic-pituitary-adrenal axis change. ${ }^{36}$ Lower blood levels of allopregnanolone, an important neurosteroid, are found in patients with psychosis and also in females with PCDH19-GCE. ${ }^{37-39}$ Furthermore, differences in neurosteroid levels between patients with PCDH19 pathogenic variants and controls become more evident in puberty, when psychosis has its onset. ${ }^{39}$ Pilot clinical trials of allopregnanolone showed a positive effect on schizophrenia-related symptoms and cognition in patients with schizophrenia. ${ }^{40} \mathrm{~A}$ single open-label pilot study of ganaxolone, a synthetic neurosteroid, in 11 children with PCDH19GCE showed improved seizure control, but the effect on behaviour and psychiatric symptoms has not been studied. ${ }^{41}$ Second, reduced connectivity in perceptual and executive networks 
has been shown in schizophrenia. ${ }^{42}$ PCDH19 encodes a cell-cell adhesion molecule and mosaic Pcdh19 murine expression results in differential adhesion of neural progenitor cells and abnormal arrangement and sorting of cells during cortical development that likely disturbs connectivity of the brain. ${ }^{4}$ Brain network connectivity studies in females with PCDH19 pathogenic variants may shed light on the human correlate and the networks involved may aid in predicting risk for the development of schizophrenia.

\section{Psychotic disorders as later-onset manifestation of genetic disease}

The concept of a later-onset phenotype has been recognized in other genetic disorders. For instance, males who carry the Fragile X pre-mutation are unaffected until late adult life when they may develop fragile X-associated tremor/ataxia syndrome. ${ }^{43}$ Adolescents with Dravet syndrome due to a SCN1A pathogenic variant often develop a crouch gait, while adults may develop Parkinsonian features in their thirties. ${ }^{44,45}$ Such later-onset disorders will only become recognized with more access to genetic testing of older individuals, and with longitudinal observation of patients with specific genetic diseases as they age.

\section{Limitations}

This study has several limitations. It would be ideal to have the same psychiatrist see all cases, however, this is impossible as the patients are in different regions of the world, and the episodes of psychosis have occurred over many years. Also, we do not have scores on neuropsychological subscales (verbal, nonverbal, memory, processing speed and attention) and this would be very challenging in some of the patients given their severe behavioural disturbance and severity of cognitive impairment. Looking at changes in these domains before, during and after psychotic episodes would help to understand the course of these disorders in patients with PCDH19-GCE.

\section{Conclusions}

We identified schizophrenia and other psychotic disorders as a later-onset manifestation of PCDH19-GCE, occurring in a fifth of older adolescents and women. Monitoring, recognition and appropriate treatment of later-onset schizophrenia in females with PCDH19-GCE should become part of routine care in this population.

\section{Key Point Box}


- PCDH19 Girls Clustering Epilepsy (GCE) causes a distinctive phenotype of early onset clusters of seizures often triggered by fever

- We identified psychotic disorders as a later-onset feature of PCDH19-GCE in 8 females with median onset 21 years (range 11-28 years)

- We found that $21 \%$ females with PCDH19-GCE aged 11 years or older developed psychotic disorders, including schizophrenia in $15 \%$.

\section{Acknowledgements}

We thank the patients and their families for participating in our research. We thank research assistants at the Epilepsy Research Centre for their assistance.

\section{Disclosures of interest}

A.S. Bassett receives/has received research support from the Canadian Institutes of Health Research, National Institute of Mental Health, McLaughlin Foundation, and Canada Research Chairs, and reports no conflicts of interest. J.E. Sullivan is is chair of the PCDH19 Alliance Scientific Advisory Board, received salary support for contracted research from Marinus Pharmaceuticals, and is a consultant for Epygenix and has received speaking honorarium from Invitae. L.G. Sadleir has received funding for travel from Seqirus and Nutricia. I.E. Scheffer serves on the editorial boards of Neurology® and Epileptic Disorders; may accrue future revenue on a pending patent re: Therapeutic compound; has received speaker honoraria from Athena Diagnostics, UCB, GSK, Eisai, and Transgenomics; has received scientific advisory board honoraria from Nutricia, UCB and GSK, has received funding for travel from Athena Diagnostics, UCB, and GSK; and receives/has received research support from the NHMRC, ARC, NIH, Health Research Council of New Zealand, March of Dimes, the Weizmann Institute, CURE, US Department of Defense, and the Perpetual Charitable Trustees. D.M. Andrade received research support from the Ontario Brain Institute, Brain and Behaviour Foundation, McLaughlin Foundation, Dravet.ca, Genome Canada, Toronto Western and General Foundation. D.M. Andrade also serves on the editorial board of Epilepsia and is part of the ILAE Task Force on Intellectual Disability. D.M. Andrade received speaker honoraria from UCB. The remaining authors have no conflicts of interest to disclose.

\section{Ethical statement}


We confirm that we have read the Journal's position on issues in ethical publication and affirm that this report is consistent with those guidelines.

\section{References}

1. Scheffer IE, Turner SJ, Dibbens LM, et al. Epilepsy and mental retardation limited to females: An under-recognized disorder. Brain 2008; 131: 918-927.

2. Dibbens LM, Tarpey PS, Hynes K, et al. X-linked protocadherin 19 mutations cause female-limited epilepsy and cognitive impairment. Nat Genet 2008; 40: 776-781.

3. Camacho A, Simón R, Sanz R, et al. Cognitive and behavioral profile in females with epilepsy with PDCH19 mutation: Two novel mutations and review of the literature. Epilepsy Behav. 2012; 24: 134-137.

4. Pederick DT, Richards KL, Piltz SG, et al. Report Abnormal Cell Sorting Underlies the Unique X-Linked Inheritance of PCDH19 Epilepsy. Neuron 2017; 97: 1-8.

5. Depienne C, Bouteiller D, Keren B, et al. Sporadic infantile epileptic encephalopathy caused by mutations in PCDH19 resembles dravet syndrome but mainly affects females. PLoS Genet 2009; 5: e1000381.

6. de Lange IM, Rump P, Neuteboom RF, et al. Male patients affected by mosaic PCDH19 mutations: five new cases. Neurogenetics 2017; 18: 147-153.

7. Higurashi N, Nakamura M, Sugai M, et al. PCDH19-related female-limited epilepsy: Further details regarding early clinical features and therapeutic efficacy. Epilepsy Res 2013; 106: 191-199.

8. Fabisiak K, Erickson RP. A familial form of convulsive disorder with or without mental retardation limited to females: extension of a pedigree limits possible genetic mechanisms. Clin Genet 1990; 38: 353-358.

9. Ryan SG, CHance, Phillip F, Zou C-H, et al. Epilepsy and mental retardation limited to females: an X-linked dominant disorder with male sparing. Nat Genet 1997; 17: 9195.

10. Depienne C, Trouillard O, Bouteiller D, et al. Mutations and deletions in PCDH19 account for various familial or isolated epilepsies in females. Hum Mutat 2011;32: 1959-1975.

11. Dibbens LM, Kneen R, Bayly MA, et al. Recurrence risk of epilepsy and mental retardation in females due to parental mosaicism of PCDH19 mutations. Neurology 2011; 76: 1514-1519.

12. Carvill GL, Heavin SB, Yendle SC, et al. Targeted resequencing in epileptic 
encephalopathies identifies de novo mutations in CHD2 and SYNGAP1. Nat Genet 2013; 45: 1-16.

13. Homan CC, Pederson S, To TH, et al. PCDH19 regulation of neural progenitor cell differentiation suggests asynchrony of neurogenesis as a mechanism contributing to PCDH19 Girls Clustering Epilepsy. Neurobiol Dis 2018; 116: 106-119.

14. Kolc KL, Sadleir LG, Scheffer IE, et al. A systematic review and meta-analysis of 271 PCDH19-variant individuals identifies psychiatric comorbidities, and association of seizure onset and disease severity. Mol Psychiatry (in press 2018).

15. Reutens TC, Howell RA, Gebert KE, et al. Validation of a Questionnaire for Clinical Seizure Diagnosis Accurate and uniform classification of epileptic seizures is vital to clinical practice and research in. Epilepsia 1992; 33: 1065-1071.

16. American Psychiatric Association. Diagnostic and statistical manual of mental disorders: The Diagnostic and Statistical Manual of Mental Disorders, fifth Edition. American Psychiatric Association, $5^{\text {th }}$ ed. Washington DC; 2013.

17. Fisher RS, Cross JH, French JA, et al. Operational classification of seizure types by the International League Against Epilepsy. Epilepsia [online serial] 2017; **(*):1-9. Available at www.ilae.org. Accessed March 2018

18. Scheffer IE, Berkovic S, Capovilla G, et al. ILAE classification of the epilepsies: Position paper of the ILAE Commission for Classification and Terminology. Epilepsia [online serial] 2017; **(*):1-10. Available at www.ilae.org. Accessed March 2018.

19. Richards S, Aziz N, Bale S, et al. Standards and Guidelines for the Interpretation of Sequence Variants: A Joint Consensus Recommendation of the American College of Medical Genetics and Genomics and the Association for Molecular Pathology. Genet Med 2015; 17: 405-424.

20. Logsdail S, Toone B. Post-ictal psychoses. A clinical and phenomenological description. Br J Psychiatry 1988; 152: 246-252.

21. Devinsky O. Postictal Psychosis: Common, Dangerous, and Treatable. Epilepsy Curr 2008; 8: 31-34.

22. Miller DT, Adam MP, Aradhya S, et al. Consensus Statement: Chromosomal Microarray Is a First-Tier Clinical Diagnostic Test for Individuals with Developmental Disabilities or Congenital Anomalies. Am J Hum Genet 2010; 86: 749-64.

23. Andrade DM, Bassett AS, Bercovici E, et al. Epilepsy: Transition from pediatric to adult care. Recommendations of the Ontario epilepsy implementation task force. Epilepsia 2017; 58: 1502-1517. 
24. Thiffault I, Farrow E, Smith L, et al. PCDH19-related epileptic encephalopathy in a male mosaic for a truncating variant. Am J Med Genet Part A 2016; 170: 1585-1589.

25. Terracciano A, Specchio N, Darra F, et al. Somatic mosaicism of PCDH19 mutation in a family with low-penetrance EFMR. Neurogenetics 2012; 13: 341-345.

26. Perälä O, Suvisaari A, Saarni SI, et al. Lifetime Prevalence of Psychotic and Bipolar I Disorders in a General Population. Arch Gen Psychiatry 2007; 64: 19-28.

27. Cooper S-A, Smiley E, Morrison J, et al. Mental ill-health in adults with intellectual disabilities: prevalence and associated factors. Br J Psychiatry 2007; 190: 27-35.

28. Morgan VA, Leonard H, Bourke J, et al. Intellectual disability co-occurring with schizophrenia and other psychiatric illness: Population-based study. Br J Psychiatry 2008; 193: 364-372.

29. Marín JL, Rodríguez-Franco MA, Chugani VM, et al. Prevalence of Schizophrenia Spectrum Disorders in Average-IQ Adults with Autism Spectrum Disorders: A Metaanalysis. J Autism Dev Disord 2018; 48: 239-250.

30. Clancy MJ, Clarke MC, Connor DJ, et al. The prevalence of psychosis in epilepsy; a systematic review and meta-analysis. BMC Psychiatry 2014; 14: 75.

31. Lowther C, Costain G, Baribeau DA, et al. Genomic Disorders in Psychiatry-What Does the Clinician Need to Know? Curr Psychiatry Rep 2017; 19: 82.

32. Bassett AS, Chow EWC, Husted J, et al. Clinical features of 78 adults with $22 \mathrm{q} 11$ deletion syndrome. Am J Med Genet 2005; 138 A: 307-313.

33. Lowther C, Costain G, Stavropoulos DJ, et al. Delineating the 15q13.3 microdeletion phenotype: a case series and comprehensive review of the literature. Genet Med 2015; 17: $149-157$.

34. Stone JL, O'Donovan MC, Gurling H, et al. Rare chromosomal deletions and duplications increase risk of schizophrenia. Nature 2008; 455: 237-241.

35. Marshall CR, Howrigan DP, Merico D, et al. Contribution of copy number variants to schizophrenia from a genome-wide study of 41,321 subjects. Nat Genet 2017; 49: $27-$ 35.

36. Holtzman CW, Trotman HD, Goulding SM, et al. Stress and neurodevelopmental processes in the emergence of psychosis. Neuroscience 2013; 249: 172-191.

37. Cai HL, Zhou X, Dougherty GG, et al. Pregnenolone-progesterone-allopregnanolone pathway as a potential therapeutic target in first-episode antipsychotic-naïve patients with schizophrenia. Psychoneuroendocrinology 2018; 90: 43-51.

38. Tan C, Shard C, Ranieri E, et al. Mutations of protocadherin 19 in female epilepsy 
(PCDH19-FE) lead to allopregnanolone deficiency. Hum Mol Genet 2015; 24: 52505259.

39. Trivisano M, Lucchi C, Rustichelli C, et al. Reduced steroidogenesis in patients with PCDH19-female limited epilepsy. Epilepsia 2017; 58: e91-e95.

40. Marx CE, Bradford DW, Hamer RM, et al. Pregnenolone as a novel therapeutic candidate in schizophrenia: Emerging preclinical and clinical evidence. Neuroscience. 2011; 191: 78-90.

41. Lappalainen J, Chez M, Sullivan J, et al. A multicenter, Open-label Trial of Ganaxolone in Children with PCDH19 Epilepsy. Presented at the $69^{\text {th }}$ Annual AAN Annual Meeting, April 2017, Boston.

42. Li P, Fan TT, Zhao RJ, et al. Altered Brain Network Connectivity as a Potential Endophenotype of Schizophrenia. Sci Rep 2017; 7: 5483.

43. Hagerman RJ, Leehey M, Heinrichs W, et al. Intention tremor, parkinsonism, and generalized brain atrophy in male carriers of fragile X. Neurology 2001; 57: 127-130.

44. Rodda JM, Scheffer IE, McMahon JM, et al. Progressive gait deterioration in adolescents with Dravet syndrome. Arch Neurol 2012; 69: 873-878.

45. Fasano A, Borlot F, Lang AE, et al. Antecollis and levodopa-responsive parkinsonism are late features of Dravet syndrome. Neurology 2014; 82: 2250-2251.

\section{Figure legends}

Figure 1: Pedigrees of 8 females with $\mathrm{PCDH} 19$ Girls Clustering epilepsy and psychotic

disorders in 7 families. Females with a psychotic disorder are marked by a red box. Girls with a mild PCDH19-GCE had mild epilepsy and intellectual disability and those with a severe $P C D H 19-G C E$ had severe epilepsy and moderate to severe intellectual disability.

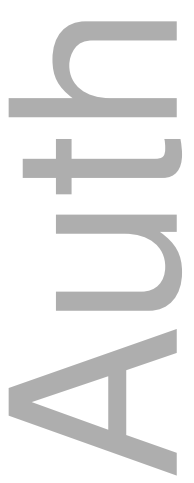


Table 1: Schizophrenia and other psychotic disorders in 8 females with $P C D H 19$ pathogenic variants

\begin{tabular}{|c|c|c|c|c|c|c|c|c|}
\hline & A:III: ${ }^{1}$ & B:III:4 ${ }^{1}$ & C:II:1 & D:IV:1 & D:IV:2 & E:II:4 & F:II:1 & G:IV:4 \\
\hline Age at study (y) & 25 & 64 & 35 & 29 & 21 & 27 & 23 & 27 \\
\hline $\begin{array}{l}\text { Pathogenic variant, } \\
\text { inheritance }\end{array}$ & p.Val441Glu, pat & p.Gln85*, UK & p.Lys708Argfs*9, UK & Exon 6 deletion, mat & Exon 6 deletion, mat & p.Leu25Pro, mat $^{2}$ & p.Ser845Asn, not mat & p.Arg911Gln, pat \\
\hline $\begin{array}{l}\text { Age at seizure onset: } \\
\text { seizure types }\end{array}$ & $12 \mathrm{m:} \mathrm{GTCS}$ & $12 \mathrm{~m}: \mathrm{FS}, \mathrm{GTCS}$ & 9 m: FMS, FIAS, CSE & $14 \mathrm{~m}:$ FBTCS & 19 m: T, FIAS, FBTCS & $\begin{array}{l}7 \text { m: FS, GTCS, At, T, SE, } \\
\text { FIAS }\end{array}$ & $8 \mathrm{~m}: \mathrm{TCS}$ & $\begin{array}{l}7 \text { y: Abs, T, GTCS, AtAbs, } \\
\text { FIAS }\end{array}$ \\
\hline Development & Always delayed & - & Delay since $9 \mathrm{~m}$ & Delay since $14 \mathrm{~m}$ & Delay since $19 \mathrm{~m}$ & Yes & - & Delay noted at $3 \mathrm{y}$ \\
\hline Regression (age) & $-(1)$ & - & Yes $(9 \mathrm{~m})$ & Language $(14 \mathrm{~m})$, delay since & Yes $(19 \mathrm{~m})$ & Yes $(7 \mathrm{~m}$ and language at $2 \mathrm{y})$ & - & Language (7 y) \\
\hline $\begin{array}{l}\text { Intellectual disability } \\
\text { (IQ) }\end{array}$ & $\begin{array}{l}\text { Mild } \\
\text { (68) }\end{array}$ & $\begin{array}{l}\text { No, but borderline intellect } \\
\text { (77; VIQ 85, PIQ 72) }\end{array}$ & Mild & $\begin{array}{l}\text { Mild } \\
\text { (62; VIQ 61, PIQ 72) }\end{array}$ & Mild & \begin{tabular}{|l} 
Severe \\
(20 single words)
\end{tabular} & $\begin{array}{l}\text { Moderate } \\
(48-49)\end{array}$ & Moderate \\
\hline $\begin{array}{l}\text { Psychiatric and behavioural } \\
\text { problems before psychosis } \\
\text { onset (age at onset) }\end{array}$ & & UK & $\begin{array}{l}\text { Depression, anxiety, } \\
\text { aggression, self-injury, } \\
\text { running away (21y) }\end{array}$ & ASD (12y) & $\begin{array}{l}\text { Aggression and anxiety (<6y), } \\
\text { ASD (6y) }\end{array}$ & $\begin{array}{l}\text { Aggression, self-injury, } \\
\text { anxiety (early age), ASD ( } 3.5 \\
\text { y), running away ( } 5 \text { y) }\end{array}$ & $\begin{array}{l}\text { Challenging behaviours and } \\
\text { suicidal gestures }(15 \mathrm{y})\end{array}$ & - \\
\hline Age at psychosis onset & $23 y$ & $21 \mathrm{y}$ & 28 y $10 \mathrm{~m}$ & $20 \mathrm{y} 4 \mathrm{~m}$ & 18 y $2 \mathrm{~m}$ & $11 \mathrm{y}$ & $19 \mathrm{y}$ & $19-20 y$ \\
\hline $\begin{array}{l}\text { Ongoing seizures at } \\
\text { psychosis onset: seizure } \\
\text { treatment }\end{array}$ & $\begin{array}{l}\text { None for } 15 \mathrm{y}: \\
\text { no AED }\end{array}$ & $\begin{array}{l}\text { Yes, } 2 \text { per year: } \\
\text { AED }\end{array}$ & $\begin{array}{l}\text { Yes: } \\
\text { CBM, LEV }\end{array}$ & $\begin{array}{l}\text { Yes, } 2-4 \text { clusters yearly: } \\
\text { CLB, TPM, PHE }\end{array}$ & $\begin{array}{l}\text { Yes, single GTC last } \\
\text { year: AED }\end{array}$ & $\begin{array}{l}\text { Yes, few yearly until } 15 \text { y: } \\
\text { AED }\end{array}$ & $\begin{array}{l}\text { Yes, breakthrough seizures } \\
\text { with AED change: AED }\end{array}$ & $\begin{array}{l}\text { Yes, every few weeks: } \\
\text { TPM, CLB, LMT, VPA }\end{array}$ \\
\hline Duration of initial episode & Few months & 12 months admitted & UK & $1-2$ weeks & $>1.5$ years & Continuous & UK & 5 years, following a SE \\
\hline - Delusions & Persecutory & Religious and grandiose & UK & - & Making up stories & - & - & Erotomanic \\
\hline - Hallucinations & Auditory & Auditory & UK & Auditory & - & Visual & Auditory & Auditory \\
\hline - Disorganized thinking & Poor cognitive insight & $\begin{array}{l}\text { Irritational, poor cognitive } \\
\text { insight }\end{array}$ & Threatened to cut out fetus & - & - & $\begin{array}{l}14 \mathrm{y} \text { : clear thought disorder } \\
\text { for } 2 \text { weeks while on RSP }\end{array}$ & - & Yes \\
\hline $\begin{array}{l}\text { - Grossly disorganized or } \\
\text { abnormal motor behaviour }\end{array}$ & $\downarrow$ motor behaviour & $\begin{array}{l}\text { Sentenced for aggression to } \\
\text { her child }\end{array}$ & UK & - & $\begin{array}{l}\text { Catatonia (stands still for } \\
\text { hours, excitable) }\end{array}$ & $\begin{array}{l}\text { Behavioural deterioration } \\
\text { with severe aggression }\end{array}$ & - & \begin{tabular}{|l|} 
Aggression \\
\end{tabular} \\
\hline - Negative symptoms & $\begin{array}{l}\text { Deterioration self-care, social } \\
\text { withdrawal, alogia, flat affect }\end{array}$ & - & Dysthymia & - & $\begin{array}{l}\text { Avolition, social withdrawal, } \\
\text { alogia }\end{array}$ & - & - & - \\
\hline $\begin{array}{l}\text { - Other symptoms related to } \\
\text { psychotic symptoms }\end{array}$ & $\begin{array}{l}\text { Suicididal ideation, anxiety, } \\
\text { agoraphobia, panic } \\
\end{array}$ & \begin{tabular}{|l} 
Grossly disorganized affect \\
\end{tabular} & UK & - & $\begin{array}{l}\text { Decline in functioning and } \\
\text { scholastic abilities }\end{array}$ & - & - & $\begin{array}{l}\text { Psychotic event preceded by } \\
\text { romantic obsession with } \\
\text { cognitive regression }\end{array}$ \\
\hline $\begin{array}{l}\text { Treatment commenced } \\
\text { after psychosis onset } \\
\left(\text { effect) }{ }^{3}\right.\end{array}$ & $\begin{array}{l}T F P \text {, VLF, } C L P \text {, CBM (non- } \\
\text { compliant), admitted, } \boldsymbol{T F P} \\
\operatorname{depot}(+/-), \mathrm{SRT}(+)\end{array}$ & $T D Z(+)$ & $\begin{array}{l}\text { RSP (non-compliant), RSP } \\
\text { consta (+), OLZ (+, but } \\
\text { briefly) }\end{array}$ & - & $\underline{R S P}(+), O L Z(-), \underline{\operatorname{LEV}(+)}$ & $\begin{array}{l}\text { QTP (-), RSP (-). } \\
\text { Currently on: } \underline{\text { OLZ, CLZ, }} \\
\underline{\text { FVX (ongoing visual }} \\
\text { hallucinations) }\end{array}$ & UK (+) & $\begin{array}{l}\boldsymbol{H L P}(\uparrow s z .), \operatorname{PHE}(-), \underline{Q T P} \\
\underline{(+)}, \underline{\operatorname{PRZ}(\mathrm{UK})}\end{array}$ \\
\hline
\end{tabular}

This article is protected by copyright. All rights reserved 
Vlaskamp et al 18

\begin{tabular}{|c|c|c|c|c|c|c|c|c|}
\hline $\begin{array}{l}\text { Recurrent psychotic } \\
\text { episodes }\end{array}$ & $\begin{array}{l}24 \text { y } 7 \text { m: Auditory } \\
\text { hallucinations with suicidal } \\
\text { ideation }\end{array}$ & $\begin{array}{l}25 \text { y: Religious delusions, } \\
\text { delusions of reference, } \\
\text { hypomania and aggression. }\end{array}$ & \begin{tabular}{|l|}
-30 y $4 \mathrm{~m}$ : Auditory \\
hallucinations, aggression, \\
social withdrawal, anhedonia \\
with suicidal attempts, less \\
sleep, anxiety, feelings of guilt \\
-33 y $10 \mathrm{~m}$ : delusions \\
(bizarre, persecutory, somatic, \\
of reference) poor cognitive \\
insight, incoherent speech \\
\end{tabular} & \begin{tabular}{|l|}
-21.5 y: Persecutory and \\
religious delusions, auditory \\
and visual hallucinations, \\
fire-setting behaviour, social \\
withdrawal, deterioration \\
self-care and alogia \\
(mimicking a depression) for \\
1.5 years following a cluster \\
of seizures \\
$-26-28$ y: twice psychosis \\
deterioration when trying to \\
switch OLZ into APZ
\end{tabular} & | & NA & $\begin{array}{l}-23 \text { y: Two relapses with } \\
\text { hallucinations and behavioral } \\
\text { deterioration } \\
-23 \text { y: Disorientation, for } \\
\text { which she was admitted a } \\
\text { month }\end{array}$ & $\begin{array}{l}\text { Frequent relapses when trying } \\
\text { to reduce QTP }\end{array}$ \\
\hline Seizures at last recurrence & None for $16 y$ & None for $>1$ year & None for $>3$ years & None for $>4$ years & $\mathrm{NA}$ & $\mathrm{NA}$ & Yes, breakthrough seizures & Yes, every few weeks \\
\hline $\begin{array}{l}\text { Treatment commenced after } \\
\text { psychosis recurrences }^{\left(\text {(ffect }^{3}\right)^{3}}\end{array}$ & $\begin{array}{l}\text { RSP (galactorrea), admitted, } \\
\underline{\text { OLZ }(+)}\end{array}$ & $C L P(+)$ & $\begin{array}{l}R S P(+), \underline{D L X}(+), Q T P(-), \\
P L P(U K), \underline{H L P \text { with }} \\
\text { benztropine (+) }\end{array}$ & $\begin{array}{l}\text { CLZ (+), RSP (+/-), VPA (-), } \\
\text { OLZ }(+, \uparrow \text { weight }), \mathrm{LEV} \\
\text { (UK) } \operatorname{APZ}(-), C L P(+), \underline{H L P} \\
(+)\end{array}$ & NA & $\mathrm{NA}$ & $\begin{array}{l}L M P(-), \mathrm{ZPM}(-), \text { Currently } \\
\text { stable on } \underline{\mathrm{VPA}}, \underline{\mathrm{LEV}}, \underline{\boldsymbol{H L P}} \\
\text { with procyclidine, } \underline{\mathrm{APM}}\end{array}$ & \\
\hline $\begin{array}{l}\text { Psychotic diagnosis } \\
\end{array}$ & Schizophrenia & Schizoaffective disorder & Schizophrenia & Schizophrenia & \begin{tabular}{|l|} 
Schizophrenia with \\
catatonia
\end{tabular} & Schizophrenia & $\begin{array}{l}\text { Unspecified } \\
\end{array}$ & Schizophrenia \\
\hline $\begin{array}{l}\text { Psychiatric outcome } \\
\end{array}$ & $\begin{array}{l}\text { Multiple episodes, currently in } \\
\text { remission with treatment. } \\
\text { Ongoing PTSD with panic } \\
\text { attacks after sexual assault }\end{array}$ & \begin{tabular}{|l} 
Multiple episodes with \\
progressive worsening, \\
currently in remission on \\
treatment (occasional \\
outbursts of aggressiveness)
\end{tabular} & $\begin{array}{l}\text { Multiple episodes, currently in } \\
\text { remission with treatment. }\end{array}$ & $\begin{array}{l}\text { Multiple episodes, currently } \\
\text { in remission with treatment. } \\
\text { Ongoing major depressive } \\
\text { disorder. }\end{array}$ & $\begin{array}{l}\text { Single long episode, currently } \\
\text { in remission with treatment. }\end{array}$ & Continuous hallucinations & $\begin{array}{l}\text { Multiple episodes, currently in } \\
\text { partial remission; persistent } \\
\text { auditory hallucinations; } \\
\text { sedated }\end{array}$ & $\begin{array}{l}\text { Multiple episodes, currently in } \\
\text { remission with antipsychotic } \\
\text { treatment }\end{array}$ \\
\hline
\end{tabular}

' Patient has previously been published by Scheffer et al. 2008.

${ }^{2}$ Mother is mosaic for $P C D H 19$ pathogenic variant.

${ }^{3}$ Treatment effect: - ineffective, + effective.

Underlined treatment is currently used.Bold and italic treatment concerns an anti-psychotic drug. Mutations were reported according to transcript NM_001184880.1

Abbreviations: $\mathrm{Abs}=$ absences, $\mathrm{AED}=$ anti-epileptic drugs, $\mathrm{AH}=$ auditory hallucinations, $\mathrm{APM}=$ alprazolam, $\mathrm{APZ}=$ aripriprazole, $\mathrm{ASD}=$ autism spectrum disorder, At = atonic seizures, AtAbs = atypical absences, $\mathrm{CBM}=$ carbamazepine, $\mathrm{CLP}=$ chlorpromazine, $\mathrm{CLZ}=$ clonazepam, $\mathrm{CSE}=$ convulsive status epilepticus, $\mathrm{DLX}=$ duloxetine, $\mathrm{FBTS}=$ focal evolving to bilateral tonic seizures, FMS $=$ focal motor seizures, FIAS = focal impaired awareness seizures, $\mathrm{FS}=$ febrile seizures, FSIQ = fullscale intellectual quotient, $\mathrm{FPT}=$ flupenthixol, $\mathrm{FVX}=$ fluvoxamine, $\mathrm{GTCS}=$ generalized tonic clonic seizures, $\mathrm{HLP}=$ haloperidol, $\mathrm{ID}=$ intellectual disability, $\mathrm{IQ}=$ intellectual quotient, $\mathrm{LEV}=$ levetiracetam, $\mathrm{m}=$ month, mat $=$ maternally inherited, $\mathrm{LMP}$ = levomepromazine, $\mathrm{LMT}=$ lamotrigine, $\mathrm{NA}=$ not applicable, $\mathrm{NVLD}=$ non-verbal learning disability, $\mathrm{OLZ}=$ olanzapine, pat $=$ paternally inherited, $\mathrm{PHE}=$ phenytoin, $\mathrm{PIQ}=$ performal intellectual quotient, $\mathrm{PLP}=$ paliperidone, $\mathrm{PRZ}=$ prazosin, $\mathrm{PTSD}=$ post-traumatic stress disorder, $\mathrm{QTP}=$ quetiapine, $\mathrm{SE}=$ status epilepticus, $\mathrm{SRT}=$ sertraline, sz. $=$ seizure, $\mathrm{T}=$ tonic seizures, $\mathrm{TDZ}=$ thioridazine, $\mathrm{TFP}=$ trifluoperazine, $\mathrm{TPM}=$ topiramate, $\mathrm{UK}=$ unknown, $\mathrm{VLF}=$ venlafaxine, $\mathrm{VPA}=\mathrm{valproate}, \mathrm{VH}=$ visual hallucinations, $\mathrm{VIQ}=$ verbal intellectual quotient, $\mathrm{y}=$ year, $\mathrm{ZPM}=$ zolpidem.

This article is protected by copyright. All rights reserved 
Table 2: Grossly disorganised behaviour in 3 females with a $\mathrm{PCDH19}$ pathogenic variant

\begin{tabular}{|c|c|c|c|}
\hline & Patient B:V:20 & Patient E:II:5 & Patient I \\
\hline Age at study (y) & 17 & 15 & 13 \\
\hline Pathogenic variant, inheritance & p.Gln85*, paternal & p.Leu25Pro, mother mosaic & p.Asp412Gly, maternal $^{1}$ \\
\hline Development & Delay since $11 \mathrm{~m}$ & Delay since $8 \mathrm{~m}$ & Always delayed \\
\hline Regression (age) & Yes $(11 \mathrm{~m})$ & Yes $(8 \mathrm{~m})$ & Frequent regression with SE \\
\hline Intellectual disability; speech & Severe: $20-30$ single words & Moderate: limited speech & Severe: single words \\
\hline $\begin{array}{l}\text { Behavioural problems before deterioration } \\
\text { (age at onset) }\end{array}$ & Tantrums, autistic features (since early age) & ADHD, OCD, ASD, aggression (<13 y) & $\begin{array}{l}\text { Aggression and anxiety (since early age), ASD } \\
(12 \mathrm{y})\end{array}$ \\
\hline Age at seizure onset: seizure types & $11 \mathrm{~m}$ : GTCS, FIAS, Abs, FS & $8 \mathrm{~m}: \mathrm{T}$, FBTCS, aura, Abs, GTCS, CSE, FS & 2 w: Abs, M, FIAS, UTCS, DA, spasms, SE \\
\hline Age at onset behavioural deterioration & $10 \mathrm{y}$ & $11-12 \mathrm{y}$ & $12 \mathrm{y}$ \\
\hline $\begin{array}{l}\text { Seizures at behavioural deterioration onset: } \\
\text { seizure treatment }\end{array}$ & Yes: CBM, CLB & Yes, clusters every 6-8 weeks till 13 y: UK & Yes: $\underline{\text { VPA }}, \underline{\mathrm{ZNS}}, \underline{\mathrm{CLB}}$ \\
\hline Initial presenting symptoms & $\begin{array}{l}\text { Intermittent episodes of anger and difficult } \\
\text { behaviour characterized by tantrums, aggression, } \\
\text { restlessness and self-injury }\end{array}$ & $\begin{array}{l}\text { Cognitive and functioning deterioration with } \\
\text { aggression to the point of requiring police } \\
\text { intervention at home on multiple occasions and } \\
\text { suspension from school }\end{array}$ & $\begin{array}{l}\text { Cognitive and functioning deterioration from age } \\
12 \text { y with severe difficulties with transition, } \\
\text { violence and aggression to the point that the } \\
\text { family cannot leave the house. }\end{array}$ \\
\hline Evolution of symptoms & $\begin{array}{l}16 \mathrm{y} \text { : easily frustrated, labile, inappropriate sexual } \\
\text { touching of herself and others }\end{array}$ & $\begin{array}{l}\text { Continuous intermittent aggression and running } \\
\text { away }\end{array}$ & Continuous intermittend aggression \\
\hline $\begin{array}{l}\text { Treatment commenced for behavioural } \\
\text { deterioration (effect) }{ }^{2}\end{array}$ & $\boldsymbol{H L P}(+)$, CLN (-), SRT (-), $\boldsymbol{Q T P}(-)$ & $\begin{array}{l}\boldsymbol{R S P}(\boldsymbol{U K K}) \text {. Currently on: } \underline{\operatorname{QTP}(-),}, \underline{\mathrm{FVX}(-), \mathrm{CLZ}} \\
(+), \underline{\mathrm{TPM}(+)}\end{array}$ & $R S P($ high prolactin), $\underline{A P Z(-)}$ \\
\hline
\end{tabular}

${ }^{1}$ This girl also has a p.Ser218Leu pathogenic variant in CACNA1A that was not maternally inherited

${ }^{2}$ Treatment effect: - ineffective, + effective.

Underlined treatment is currently used. Bold and italic treatment concerns an anti-psychotic drug. Variants were reported according to transcript NM_001184880.1

Abbreviations: $\mathrm{Abs}=$ absences, $\mathrm{ADHD}=$ attention deficit hyperactivity syndrome, $\mathrm{APZ}=$ aripriprazole, $\mathrm{ASD}=$ autism specrum disorder, $\mathrm{CBM}=$ carbamazepine, $\mathrm{CLB}=$ clobazam $, \mathrm{CLN}=\mathrm{clonidine}, \mathrm{CLZ}=$ clonazepam, $\mathrm{CSE}=$ convulsive status epilepticus, $\mathrm{CT}=$ computotomotography, $\mathrm{DA}=$ drop attacks, $\mathrm{ED}=$ epileptic discharges, FBTCS $=$ focal evolving to bilateral tonic-clonic seizures, FIAS = focal impaired awareness seizures, FS = febrile seizures, FSIQ = full-scale intellectual quotient, FVX = fluvoxamine, GTCS = generalized tonic clonic seizures, HLP = haloperidol, ID = intellectual disability, $\mathrm{L}=$ left, $\mathrm{M}=$ myoclonic

This article is protected by copyright. All rights reserved 
seizures, $\mathrm{m}=$ month, $\mathrm{ODD}=$ obsessive compulsive disorder, $\mathrm{QTP}=$ quetiapine, $\mathrm{RSP}=$ risperidone, $\mathrm{SE}=$ status epilepticus, $\mathrm{SRT}=$ sertraline, $\mathrm{sz} .=$ seizure, $\mathrm{T}=$ tonic seizures, $\mathrm{TPM}=$ topiramate, $\mathrm{UTCS}=$ unknown onset tonic-clonic seizures, VPA $=$ valproate, $\mathrm{w}=$ weeks, $\mathrm{y}=$ year, $\mathrm{ZNS}=$ zonisamide .

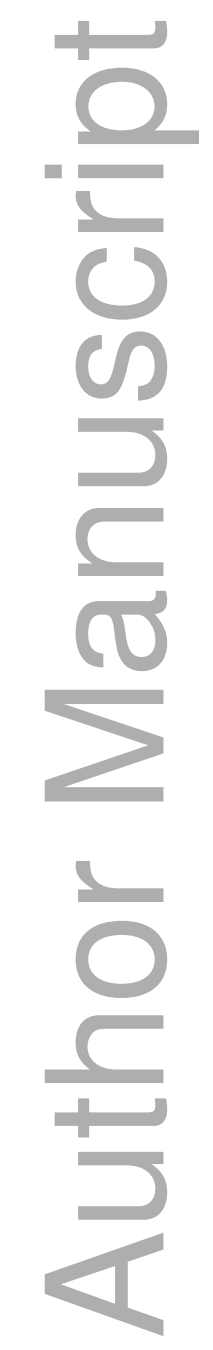

This article is protected by copyright. All rights reserved 


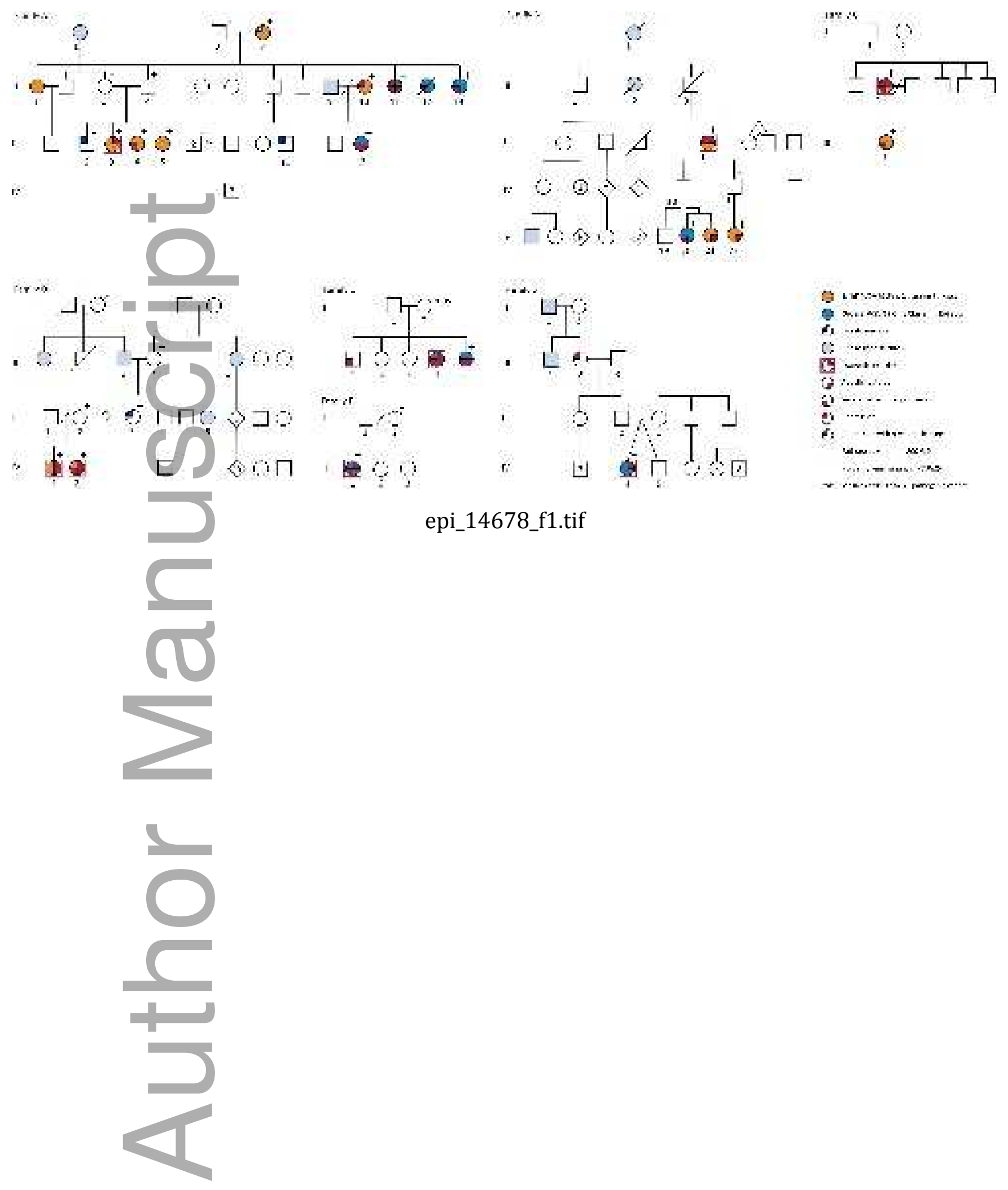

This article is protected by copyright. All rights reserved 


\section{University Library}

\section{- M M N E R VA A gateway to Melbourne's research publications}

Minerva Access is the Institutional Repository of The University of Melbourne

Author/s:

Vlaskamp, DRM;Bassett, AS;Sullivan, JE;Robblee, J;Sadleir, LG;Scheffer, IE;Andrade, DM

Title:

Schizophrenia is a later-onset feature of PCDH19 Girls Clustering Epilepsy

Date:

2019-03-01

Citation:

Vlaskamp, D. R. M., Bassett, A. S., Sullivan, J. E., Robblee, J., Sadleir, L. G., Scheffer, I. E. \& Andrade, D. M. (2019). Schizophrenia is a later-onset feature of PCDH19 Girls Clustering Epilepsy. EPILEPSIA, 60 (3), pp.429-440. https://doi.org/10.1111/epi.14678.

Persistent Link:

http://hdl.handle.net/11343/285531 